\title{
Perbaikan Teknik Relining Tanur Induksi Untuk Mencegah Terbentuknya Rongga Lining dan Penghematan Biaya Proses Peleburan
}

\author{
Tri Daryanto*, Sutoyo, Mansur Hidayat \\ Program Studi D3 Teknik Pengecoran Logam, Politeknik Manufaktur Ceper, Klaten-Jawa Tengah \\ *Penulis Korespondensi: anto.tridaryanto@gmail.com
}

Histori artikel: diserahkan 10 Februari 2020, direviu 12 Februari 2020, direvisi 02 Maret 2020

\begin{abstract}
The lining is coil's protector component and metal liquid reservoir, the lining is required to own endurance towards chemical reaction and high temperature emitted by the smelting process. The lining commonly problem on the lining damage (cavity) after the sintering process. This damage causes the smelting process force-stopped, due to endangering the induction furnace operator and the surrounding. According to the analysis result, the lining damage occured because of the improper pulverization and sintering process with the casting term. The uncontinued compression process and the improper sintering with the used fireproof material cause the lining not to be function maximally. The upcoming refinement will apply the proper compression process according to metal casting theories and economically analyzed.
\end{abstract}

Keywords: lining, sintering, induction, furnace

DOI: $10.18196 /$ jqt.010211

Web: http://journal.umy.ac.id/index.php/qt

\section{PENDAHULUAN}

Tanur induksi merupakan alat yang sangat penting dalam industri pengecoran logam. Tanur induksi berfungsi untuk mengubah bahan baku cor padat mencadi cair. Tanur induksi bekerja dengan prinsip transformator, dimana kumparan primer dialiri arus bolak balik dari sumber listrik lalu menghasilkan arus induksi dan medan magnet, lalu kumparan sekunder diletakkan di dalam medan magnet. Berbeda dengan transformator, kumparan sekunder digantikan oleh bahan baku peleburan yang dirancang sedemikian rupa agar arus induksi tersebut berubah menjadi panas yang sanggup mencairkannya (Ghosh, 2000).

Pada penelitian ini pengambilan obyek penelitian pada salah satu perusahaan pengecoran logam yang ada di wilayah jawa timur. Pengopersian tanur induksi menggunakan tanur induksi frekuensi menengah $(150 \mathrm{~Hz}-300 \mathrm{~Hz})$ dengan kapasitas $150 \mathrm{~kg}$ dan $250 \mathrm{~kg}$. Bahan tahan api yang digunakan berjenis netral, untuk melebur bahan baku baja tahan karat.
Permasalahan yang sering terjadi pada tanur induksi di perusahaan tersebut yaitu sering terbentuk rongga lining setelah proses sintering, sehingga membahayakan keselamatan jiwa dan perlu dilakukan proses penambalan. Bahan tahan api yang digunakan merupakan bahan tahan api buatan yang sudah umum digunakan di industri pengecoran logam di Indonesia.

Masalah peleburan saat ini sering ditemukannya rongga yang terbentuk pada produk disebabkan oleh proses penumbukan yang tidak merata dan terkesan buru-buru. Lining yang sudah selesai tidak segera di sintering dan dibiarkan selama selama bebarapa hari. Proses sintering yang dilakukan terlalu cepat hanya selama 4-5 jam dengan sistem on-off. Pada saat pemuatan untuk sintering, bahan baku yang dimasukan tidak masif, pejal dan ukuranya tidak seragam. Proses tersebut mengakibatkan temperatur naik secara drastis sebelum kelembaban lining hilang. Selain itu, distribusi panas menjadi tidak merata dan mengakibatkan perbedaan temperatur yang signifikan, sehingga bahan baku dan lining former mencair sebelum 
permukaan lining menjadi keramik, lalu lining yang masih berbentuk serbuk tersebut terkena penetrasi cairan dan akhirnya terbentuklah rongga (Ghosh, 2000).

Kerusakan lining secara langsung akan mempengaruhi proses produksi yang berujung terjadinya kerugian. Penulis juga akan melakukan analisa biaya proses yang ditimbulkan oleh kedua proses yang telah dilakukan.

\section{Latar Belakang}

Proses pembuatan lining tanur induksi, memerlukan pengetahuan yang benar mengenai pemilihan material tahan api, teknik penumbukan, pemuatan bahan baku dan proses sintering yang akan diterapkan. Apabila semua komponen tersebut tidak dilaksanakan dengan benar maka akan menimbulkan beberapa masalah.

Berbagai permasalahan yaitu terbentuknya rongga setelah proses sintering akibat luruhnya bahan tahan api pada permukaan lining yang masih serbuk oleh penetrasi cairan, karena bahan baku dan lining former mencair sebelum lining bagian depan menjadi keramik Permasalahan rongga ini mengakibatkan munculnya pekerjaan baru berupa penambalan, sehingga proses peleburan menjadi terhambat dan berimbas pada menurunya kapasitas produksi

\section{Landasan Teori}

Tanur induksi beroperasi menggunakan kaidah hukun faraday. Pada tahun 1831, Faraday menemukan teori pemanasan dengan media induksi (elektromagnetik). Tanur induksi adalah aplikasi dari percobaan Faraday, dimana coil yang dialiri arus bolak balik (AC) bertindak sebagai kumparan primer dan bahan peleburan sebagai kumparan sekunder. Pada saat koil dialiri arus listrik, terbentuk daerah magnetik diantara lilitan koil. Daerah magnetik menimbulkan arus putar pada kumparan sekunder yang digantikan oleh bahan baku peleburan. Intensitas arus putar menimbulkan gesekan elektron logam sehingga timbul panas yang dapat mencairkan kumparan sekunder (Ghandevar et.al, 2011).
Penggunaan tanur induksi di sektor industri pengecoran logam sudah berkembang dengan pesat. Meluasnya penggunaan tanur induksi disebabkan karena penggunaan tanur induksi untuk besi cor dianggap lebih menguntungkan dibanding menggunakan kupola atau dapur tungkik. Secara teoritis belum dapat dibuktikan bahwa tanur induksi lebih menguntungkan untuk proses peleburan besi cor.

Berdasarkan frekuensi kerja yang digunakan, tanur induksi dikategorikan menjadi tanur induksi frekuensi rendah atau tanur induksi frekuensi jala-jala $(50 \mathrm{~Hz}-60 \mathrm{~Hz})$ dengan kapasitas lebur tinggi (diatas 1 ton/jam) dan tanur induksi frekuensi menengah $(150 \mathrm{~Hz}-$ $10000 \mathrm{~Hz}$ ) dengan kapasitas lebur lebih rendah (www.hapli.wordpress.com). Penggolongan frekuensi tanur induksi dikelompokan berdasarkan sifat peleburanya. Klasifikasi tersebut ditampilkan dalam bentuk tabel perbandingan. Menurut artikel yang diterbitkan oleh Hapli (Himpunan Praktisi Pengecoran Logam Indonesia) klasifikasi tanur induksi dijabarkan melalui diagram perbandingan antara frekuensi kerja dengan kapasitas lebur. Berikut ini adalah klasifikasi tanur induksi menurut.

TABEL 1. Pembagian Jenis Tanur Induksi (Surdia, 1996)

\begin{tabular}{|c|c|c|c|c|c|}
\hline $\begin{array}{c}\text { Jenis } \\
\text { tanur } \\
\text { induksi }\end{array}$ & $\begin{array}{c}\text { Kapasitas } \\
\text { lebur }\end{array}$ & Laju & $\begin{array}{l}\text { Gaya } \\
\text { aduk }\end{array}$ & $\begin{array}{c}\text { Sifat } \\
\text { operasi }\end{array}$ & Harga \\
\hline $\begin{array}{l}\text { Frekuensi } \\
\text { tinggi jenis } \\
\text { krus }\end{array}$ & Kecil & Cepat & Lemah & $\begin{array}{l}\text { peleburan } \\
\text { temperatur } \\
\text { tinggi, dari } \\
\text { keadaan } \\
\text { dingin }\end{array}$ & Mahal \\
\hline $\begin{array}{c}\text { Frekuensi } \\
\text { rendah } \\
\text { jenis krus }\end{array}$ & $\begin{array}{c}\text { Sedang } \\
\text { Besar }\end{array}$ & Lambat & Kuat & $\begin{array}{c}\text { produksi } \\
\text { masa, } \\
\text { operasi } \\
\text { putus - } \\
\text { putus atau } \\
\text { kontinu }\end{array}$ & Murah \\
\hline $\begin{array}{l}\text { Frekuensi } \\
\text { rendah } \\
\text { jenis } \\
\text { saluran }\end{array}$ & $\begin{array}{c}\text { Sedang } \\
\text { Besar }\end{array}$ & Lambat & Kuat & $\begin{array}{c}\text { Operasi } \\
\text { kontinu, } \\
\text { efisiensi } \\
\text { panas baik, } \\
\text { ekonomis }\end{array}$ & Murah \\
\hline
\end{tabular}

\section{Tanur Induksi Frekuensi Rendah}

Keistimewaan tanur induksi frekuensi rendah adalah adanya gaya pengadukan logam cair yang cukup besar. Gaya pengadukan berguna untuk homogenisasi komposisi cairan. Gaya tersebut berbanding terbalik dengan akar 
frekuensi dan berbanding lurus dengan tenaga listrik yang diberikan. Pengaruh buruk dari gaya pengadukan adalah adanya bahaya oksidasi cairan. Jika cairan ditahan terlalu lama dalam tanur akan sangat rentan terjadi erosi lining dan menginklusi cairan. Pengikisan lining terjadi karena bahan tahan api tersinter atau karena tekanan dan gesekan yang terjadi antara lining dengan cairan yang teraduk (Ghandevar et.al, 2011).

\section{Tanur Induksi Saluran}

Perbedaan tanur induksi saluran dengan krus adalah pemanasan pada tanur induksi saluran dilakukan pada bagian saluran cairan. Bahan cair yang panas akan bergerak keatas, sedangkan bahan cair yang dingin bergerak kebawah mengisi saluran

Tanur induksi saluran membutuhkan lebih sedikit energi listrik, karena tidak memanaskan bahan baku dari keadaan dingin. Peleburan dilakukan dengan konveksi panas yang berasal dari cairan awal. Temperatur akan meningkat setelah ada proses induksi pada daerah saluran (Surdia, 1986).

\section{Tanur Induksi Krus}

Berbeda dengan tanur induksi saluran, tanur induksi krus digunakan untuk proses peleburan dari keadaan dingin sampai proses penuangan. Dibanding tanur induksi saluran, tanur induksi krus lebih populer karena fungsi dan cara penggunaanya lebih fleksibel. Tanur induksi frekuensi rendah krus umumnya digunakan untuk melebur bahan baku berbasis besi. Bahan peleburan yang biasa dibuat menggunakan tanur ini biasanya berupa besi cor, baja karbon polos dan besi cor paduan. Di beberapa industri digunakan untuk melebur bahan bukan besi seperti bronze, brass dan bahan berbasis tembaga lainya (Surdia, 1986).

\section{Tanur Induksi Frekuensi Menengah}

Secara umum, prinsip kerja tanur induksi frekuensi menengah sama dengan tanur induksi frekuensi rendah. Perbedaanya pada tanur induksi frekuensi menengah terdapat alat pengubah frekuensi yang bernama thyristor. Arus listrik bolak-balik (AC) dari sumber tenaga masuk kedalam panel tanur induksi. Thyristor mengubah frekuensi jala-jala menjadi frekuensi yang lebih tinggi lalu dialirkan ke kumparan primer.

Gerak pengadukan yang dihasilkan tanur induksi frekuensi tinggi berbeda dengan gerak pengadukan yang dihasilkan tanur induksi frekuensi rendah. Secara kualitatif, semakin tinggi frekuensi yang bekerja maka gerak pengadukan akan semakin kecil. Secara kuantitatif, semakin tinggi frekuensi kerja, maka gerak pengadukan akan semakin banyak dan merata di seluruh bagian tanur (www.Hapli.wordpress.com)

\section{Bahan Tahan Api}

Bahan tahan api adalah bahan baku industri yang dibuat sebagai bahan konstruksi atau unit industri (plan), yang berfungsi untuk menerima beban panas yang tinggi. Bahan tersebut harus mampu menahan panas minimal pada $1000^{\circ} \mathrm{C}$, bahkan terakhir telah diproduksi bahan tahan api dengan jenis basa yang mampu menahan panas hingga $2000^{\circ} \mathrm{C}$.

Tuntutan bahan tahan api adalah mampu melawan temperatur tinggi, dapat bertahan minimal tidak meleleh pada suhu yang diinginkan sesuai dengan jenis dan macamnya, mampu tidak terbakar menjadi abu atau gas terhadap pengaruh perubahan peningkatan temperatur kerja tanur induksi.

Ketahanan bahan tahan api sangat bergantung pada kandungan unsur penyusun, bentuk fisik dan bahan dasarnya. Berdasarkan bentuk fisiknya, bahan tahan api dapat berupa batuan, kerikil dan serbuk. Menurut bahan dasarnya, bahan tahan api berupa mineral dan keramik. Menurut penyusunya, ada yang berupa kuarsit, alumina, magnesit dll.

\section{Lining}

Lining adalah lapisan tanur induksi yang terbuat dari mineral keramik khusus. Bahan tahan api ini telah mengalami proses sinter dan memiliki sifat-sifat; Tahan terhadap pengaruh panas, Tahan terhadap pengaruh mekanis ,Tahan terhadap pengaruh reaksi kimia dari cairan logam

Lining mempunyai konstruksi refraktori atau bahan tahan api pada sebuah tungku induksi (Gambar 1) diawali dengan proses sintering 
terhadap refraktori untuk lining tungku yang baru sehingga bahan lining yang semula terdiri dari serbuk kasar, sebagian berubah menjadi bersifat keramik yang tahan terhadap temperatur tinggi dan pengaruh kimiawi. Hal ini dapat kita perhatikan gambar lining di bawah ini (Nugroho et al., 2011).

Bahan tahan api ini umumnya terdiri dari bahan dasar dan bahan pengikat. Bahan tahan api yang biasa digunakan tanur induksi untuk peleburan baja biasanya alumina $\left(\mathrm{Al}_{2} \mathrm{O}_{3}\right)$ yang bersifat netral dengan kemurnian $80 \%-95 \%$. Selain alumina, magnesit $(\mathrm{MgO})$ yang bersifat basa dengan kemurnian $80 \%$ - 98\% juga biasa digunakan untuk proses peleburan baja (Uylas et.al, 2015).

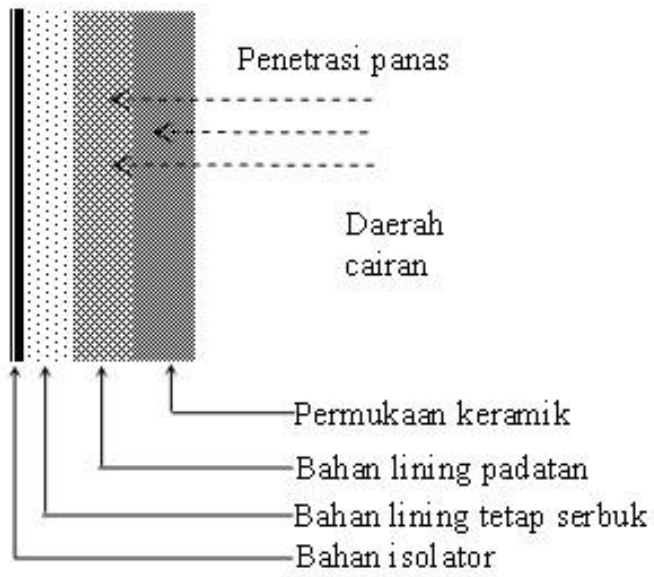

GAMBAR 1. Konstruksi Lining induksi (www.hapli.wordpress.com, diakses 2020)

Pemilihan jenis bahan pelapis atau lining harus disesuaikan dengan terak peleburan yang dihasilkan. Terak basa yang dihasilkan dari peleburan baja sangat korosif terhadap lining berkarakter asam $\left(\mathrm{SiO}_{2}\right)$, begitu pula sebaliknya. Maka perlu diketahui mengenai sifat-sifat penting bahan tahan api untuk lining (Ghosh, 2000).

\section{Pelapisan}

Berikut ini akan diuraikan mengenai pelapisan tanur induksi:

- Lakukan perbaikan lapisan pelindung kumparan dengan menggunakan semen coil

- Lapisan pertama adalah isolator (bahan fiber fax paper). Bahan ini harus dipola dan dipotong tepat seluas permukaan yang dilapisi

- Pemadatan alas tanur
- Perhatikan panjang kawat arde yang harus tepat setebal alas tanur. Padatkan hingga $\pm 5 \mathrm{~cm}$ lebih tebal dari yang diinginkan (alas tanur), kemudian buang kelebihan kepadatan $( \pm 5 \mathrm{~cm})$. Tujuannya adalah untuk mendapatkan kepadatan yang sama pada seluruh bagian.

- Pasang lining former yang telah bersih dari karat secara simetris dan kencangkan dengan baji kayu

- Pemadatan dinding tanur dilakukan bertahap hingga setinggi lining forme.

\section{METODE PENELITIAN}

Metode penelitian menggunakan pendekatan balik (reverse approach), artinya adalah bahwa analisa dimulai dari luaran, kemudian pelacakan balik ke teknologi proses. Untuk menganalisa luaran produk, ditentukan proses pengerjaan lining sebanyak 3kali. Analisa terhadap 3 proses uji dilakukan melalui pengujian kekerasan dan pemeriksaan kondisi retakan lining yang terjadi

\section{Metoda Pemadatan}

Untuk mendapatkan kepadatan yang maksimal dan merata, metoda penumbukan cetakan secara manual dapat diterapkan pada saat penumbukan bagian bawah. Metoda tersebut adalah metoda penumbukan arah menganyam dan penumbukan arah melingkar.

Teknik penumbukkan anyam memiliki arah tumbukkan seperti bentuk anyaman yang terdapat pada tikar bambu. Teknik penumbukkan ini memungkinkan untuk mencapai kepadatan atau kekerasan cetakan yang merata diseluruh bagian (Ghosh, 2004).

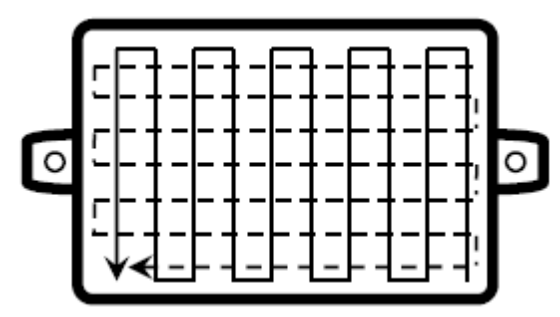

GAMbar 2. Pemadatan Menganyam (www.hapli.wordpress.com, diakses 2020) 
Arah tumbukkan dari teknik melingkar seperti spiral dan berakhir ditengah-tengah cetakan. Teknik penumbukkan seperti ini cenderung menghasilkan kepadatan atau kekerasan yang lebih kuat dibagian tengah cetakan (Ghosh, 2004)

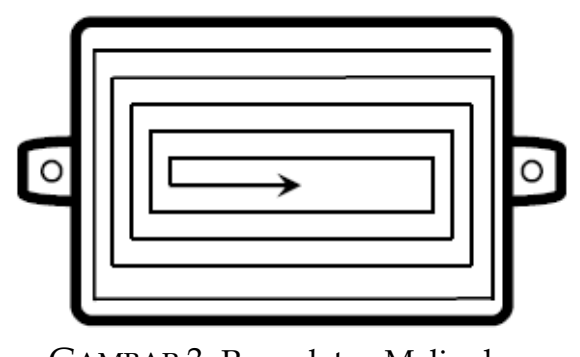

GAMBAR 3. Pemadatan Melingkar

(www.hapli.wordpress.com, diakses 2020)

\section{Proses sintering}

Untuk proses ini dibutuhkan sebuah blok sinter dengan syarat: 1) Bahan sesuai dengan kebutuhan peleburan, 2) Stabil atau bentuknya serempak, 3) Setinggi lining ,4) Bersih.

Pada proses peleburan baja, bahan tahan api untuk lining tanur induksi bisanya bersifat netral atau basa. Sebagian besar bahan tahan api basa terbuat dari mineral berbasis magnesia $(\mathrm{MgO})$. Bahan tahan api netral umumnya terbuat dari mineral berbasis alumina $\left(\mathrm{Al}_{2} \mathrm{O}_{3}\right)$ atau aluminos-silicate $\left(\mathrm{Al}_{2} \mathrm{O}_{3}-\mathrm{SiO}_{2}\right)$. Kedua jenis bahan ini tidak mengalami pemuaian yang besar. Pemanasan setelah pengeringan dapat langsung dilakukan proses pemanasan sampai temperatur sinter yang dianjurkan.

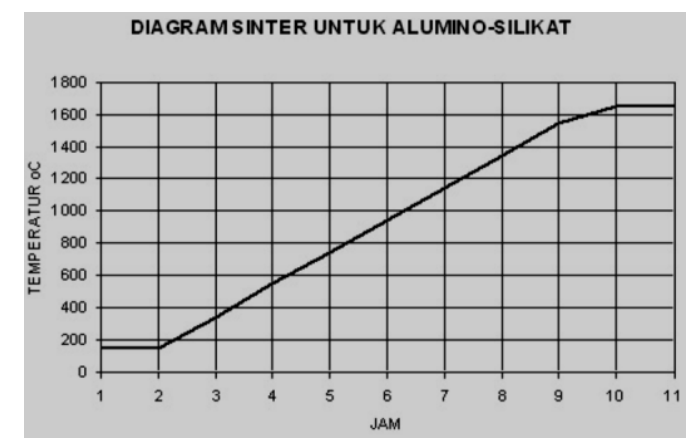

GAMBAR 4. Sintering

\section{HASIL DAN PEMBAHASAN}

\section{Analisis Hasil Sintering}

Setelah mengamati beberapa kali proses sintering yang dilakukan, penulis menemukan kerusakan yang sama baik pada lining tanur induksi kapasitas $250 \mathrm{~kg}$ maupun $150 \mathrm{~kg}$. Berikut ini beberapa kerusakan yang sering terjadi pada lining tanur induksi:

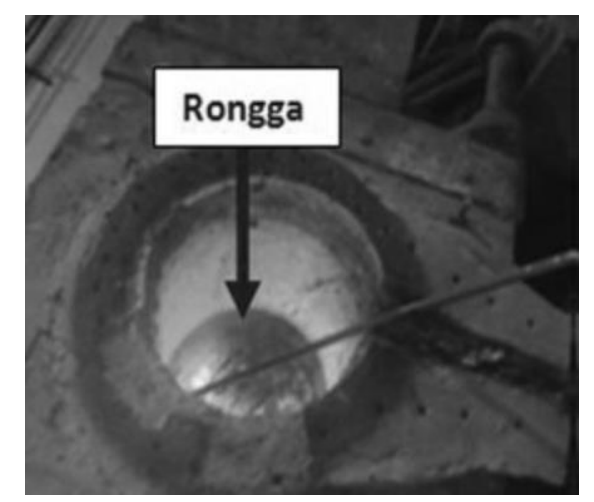

GAMBAR 5. Rongga Tanur bagian bawah

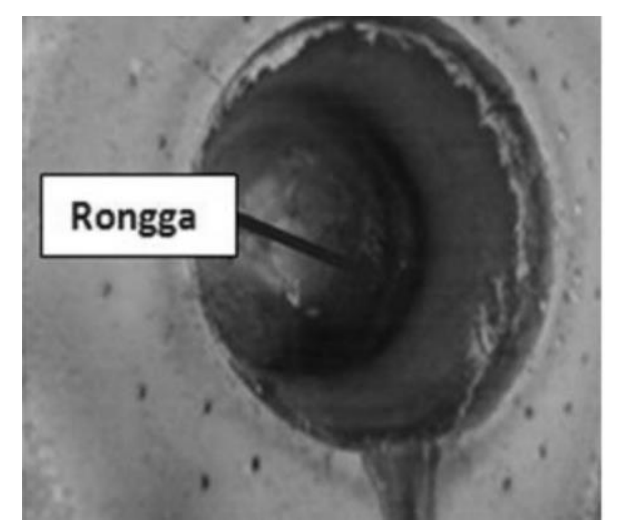

GAMBAR 6. Rongga tanur pada bagian samping

Analisis yang dilakukan penulis adalah pengamatan proses relining mulai dari pembongkaran, penambalan semen koil, pemasangan isolator, pemadatan bawah, pemasangan lining former, pemadatan samping, sintering, sampai pada penuangan. Dari hasil pengamatan tersebut terjadi beberapa penyimpangan metoda yang sangat prinsip, diantaranya:

a. Proses penumbukan tidak kontinyu dan diselesaikan selama 4 (empat) sampai 5 (lima) hari.

b. Bahan baku tidak masif dan bersih.

c. Teknik sintering tidak mengacu pada temperatur kerja 


\section{Perbaikan}

Penyimpangan pada proses tersebut terdapat 3 dan telah dilakukan 2 (dua) perbaikan, yakni perbaikan proses penumbukan dan teknik sintering. Adapun untuk perubahan bahan baku peleburan saat ini belum dapat dilakukan, dengan alasan biaya pengadaan. Namun demikian tetap dilakukan perbaikan yang mendekati prinsip dari 3 (tiga) komponen diatas.

\section{Penumbukan}

Proses penumbukan dilakukan dengan memperhatikan hal-hal berikut ini:

\section{Waktu Pengerjaan}

1) Proses penumbukan dilakukan secara terusmenerus atau kontinyu tanpa mengindahkan pekerjaan lain

2) Sedapat mungkin diselesaikan dalam waktu kurang dari satu hari dengan menyediakan teknisi khusus untuk proses penumbukan.

\section{Penumbukan Bagian Bawah}

Penumbuk yang digunakan terdiri dari 3 (tiga) bentuk dan fungsi yang berbeda. Berikut urutan penggunaanya:

\section{Penumbuk Bergerigi}

Penumbuk bergerigi dilakukan untuk proses pemadatan awal (Gambar 7). Tujuanya adalah untuk menghasilkan kepadatan maksimal yang mendekati nilai kerapatan (densitas) koral. Kepadatan didapat dari adanya gaya tekan yang besar sedangkan luas penampang gerigi kecil. Gambar 7 menunjukan tentang ilustrasi penggunaan penumbuk bergerigi.

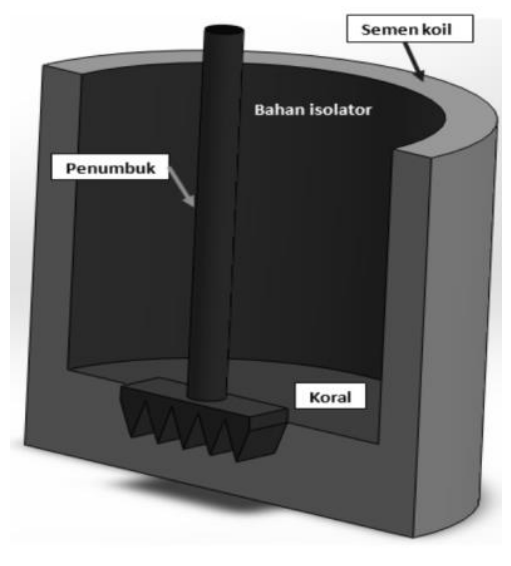

Gambar 7. Penumbukan Gerigi

\section{Penumbuk Lonjong}

Penumbuk lonjong digunakan untuk proses pemadatan akhir (Gambar 8). Penumbuk lonjong memiliki bobot paling berat. Hal ini mengacu pada pengertian prinsip gaya, bahwa besarnya gaya didapat dari perkalian antara masa benda dengan percepatanya. Percepatan sendiri didapat dari ayunan tangan saat menumbuk. Gambar dibawah ini menunjukan ilustrasi tentang penggunaan penumbuk lonjong.

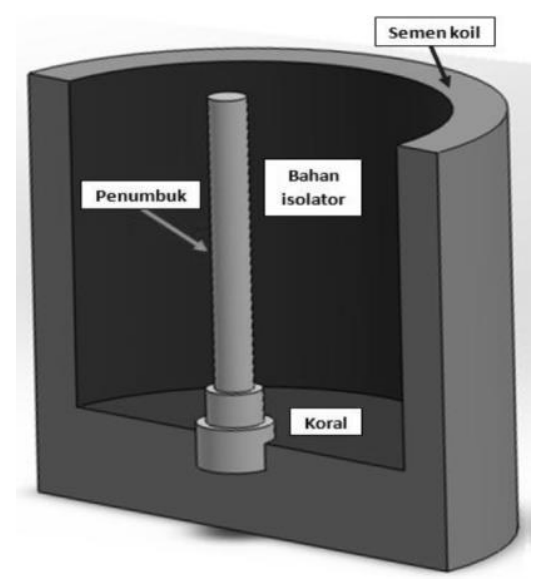

Gambar 8. Penumbukan Lonjong

\section{Penumbuk Rata}

Gambar 9 menunjukkan penumbuk rata yang dilakukan pada tahapan akhir. Tujuanya adalah untuk meratakan proses pemadatan akhir yang telah dilakukan. Dengan penumbuk ini, lining yang telah dipadatkan dengan penumbuk bergerigi dan lonjong akan memadat dengan rata, sehingga pemasangan lining former menjadi lebih mudah. 


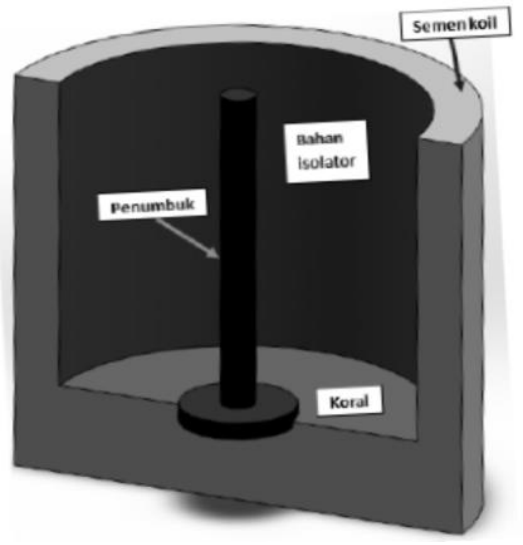

GAMBAR 9. Penumbukan Rata

\section{Metoda Penumbukan}

Metoda penumbukan yang diterapkan adalah penumbukan melingkar dan penumbukan anyam. Kedua metode tersebut dilakukan secara bergantian dan berurutan. Selanjutnya, Pemuatan bahan tahan api dilakukan secara bertahap dengan capaian ketebalan minimal $80 \mathrm{~mm}$.

\section{Penentuan Target Kepadatan}

Untuk memastikan bahwa tumbukan yang kita lakukan sudah maksimal, dapat dilakukan dengan dua cara:

a). Pemeriksaan visual. Pemeriksaan ini dapat didlihat dari hilangnya debu pada saat penumbukan

b). Menghitung berat bahan lining yang dibutuhkan.

\section{Penumbukan Bagian Samping}

Alat penumbuk menggunakan 3 (tiga) alat secara berurutan. Gambar 9 adalah ilustrasi penumbukan pada bagian samping.

Keterangan :

1) Penumbuk pipih (kanan)

2) Penumbuk Bergerigi (kiri)

3) Penumbuk lonjong (tengah)

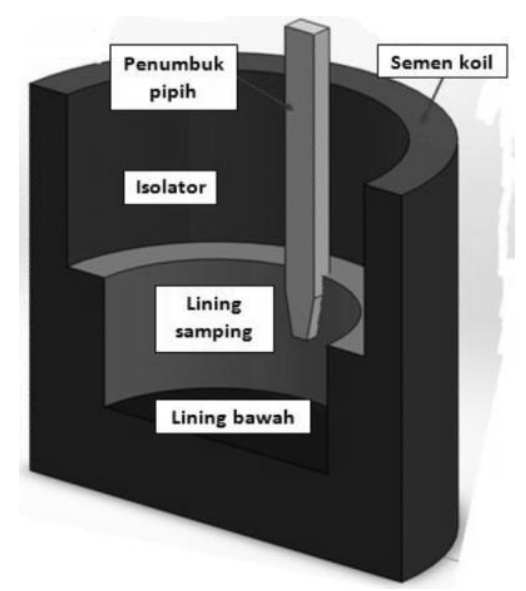

Gambar 10. Penumbukan Samping

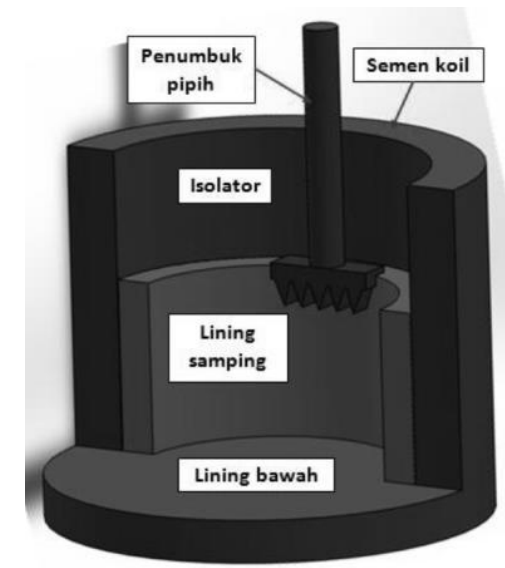

GAMBAR 11. Penumbukan Samping 2

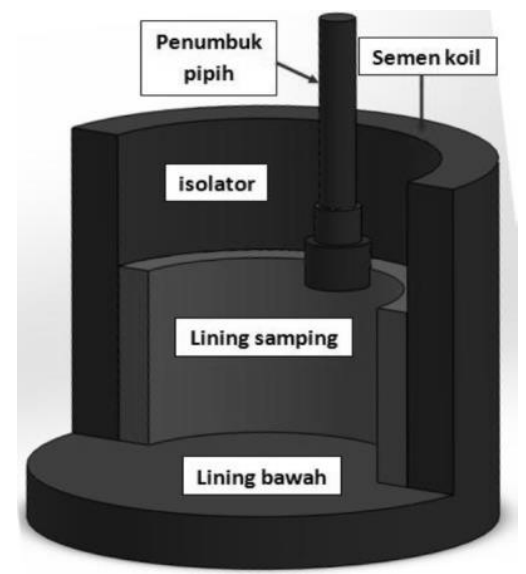

GAMBAR 12. Penumbukan Samping 3

\section{Sintering}

Teknik sintering disesuaikan dengan bahan baku dasar bahan tahan api. Bahan tahan api yang digunakan di PT A merupakan bahan tahan api netral (alumino-silikat) dengan kandungan $\mathrm{Al}_{2} \mathrm{O}_{3} 85 \%$, maka teknik sintering 
yang dilakukan harus mengikuti prinsip sintering lining netral.

Secara konsep, teknik sintering alumino-silikat yang dijelaskan melalui diagram sintering diatas dapat dikelompokan menjadi 3 (tiga) tahap. Tahap pertama adalah pemanasan awal atau preheating, dilanjutkan dengan proses peleburan dan penahanan temperatur atau holding

\section{Pemanasan Awal}

Pemanasan awal pada temperatur $150^{\circ} \mathrm{C}$ dan ditahan selama 2 jam. Proses ini dilakukan untuk menghilangkan kelembaban, sisa tegangan dan biological content yang mungkin masih terkandung dalam koral. Hal-hal tersebut harus dihilangkan secara merata sebelum proses pengkeramikan koral dilanjutkan.

\section{Peleburan}

Bahan tahan api basa atau netral tidak mengalami pemuaian yang signifikan. Setelah proses pengeringan melalui pemanasan awal, pemanasan dapat dilanjutkan secara bertahap sampai temperatur cair. Pemanasan dilakukan secara bertahap bertujuan untuk meratakan panas di setiap bagian bahan baku maupun lining former. Dengan begitu, bahan baku sintering maupun lining former akan mencair secara serampak.

\section{Penahanan}

Pada kondisi cair, temperatur bahan baku telah mencapai temperatur sinter alumino-silikat. Untuk meratakan fasa keramik di seluruh permukaan lining, cairan logam diharuskan penuh. Proses pengkeramikan koral melalui cairan logam membutuhkan waktu yang cukup agar ikatan keramik benar-benar sempurna. Untuk mencapai tujuan tersebut dilakukan penahanan cairan maksimal 1 jam. Dalam penelitian ini penulis mencoba melakukan penahanan cairan selama 10 sampai 30 menit, dengan alasan untuk menghemat waktu.

\section{Permukaan lining}

Gambar 13 merupakan foto lining tanur induksi kapasitas 250 setelah proses sintering dan beberapa kali peleburan.

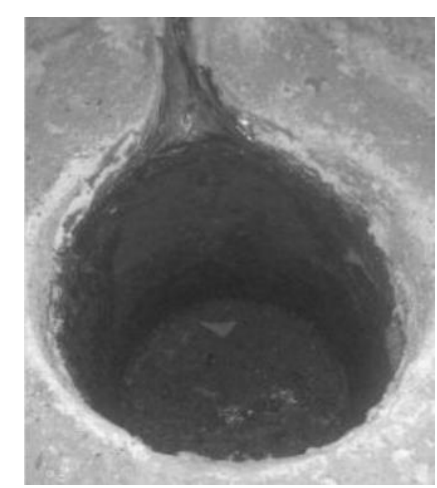

GAmbar 13. Kondisi Tanur Setelah Perbaikan

Setelah melakukan beberapa percobaan perbaikan didapatlah penjelasan hasil sebagai berikut:

1). Rongga lining pada bagian samping tidak terbentuk lagi

2). Cekungan lining pada bagian bawah tidak terbentuk lagi

\section{Data pemakaian lining}

Dibawah ini merupakan laporan mengenai kondisi dan umur pakai lining. Data yang disajikan merupakan laporan bulanan dari administrasi produks jumlah pemakaian lining semakin banyak sehingga umur lining semakin panjang sebagaimana pada gambar dibawah ini

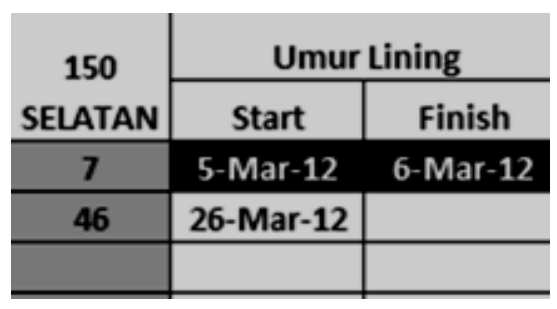

GAMBAR 14. Data Penggunaan Lining

Berdasarkan gambar penggunaan Lining di atas dapat perbedaan awalnya tanur digunakan sebanyak 7 charging. Setelah dilakukan proses perbaikan dapat digunankan menjadi 46 Charging dan masih bisa digunakan. 


\section{Analisa Ekonomis}

Analisa secara ekonomis ini merupakan analisa berdasarkan pembiyaan proses relining tanur induksi $150 \mathrm{Kg}$. Proses ini terdiri dari proses pembongkaran, pemasangan lining dan sintering. Berikut kami berikan data penggunaan material proses relining tanur induksi pada Tabel 2.

TABEL 2. Bahan relining Tanur Induksi

\begin{tabular}{|c|c|}
\hline Usia lining tanur & $\begin{array}{l}=100 \text { charging } \\
\text { (normal) }\end{array}$ \\
\hline Jumlah bahan lining terpakai & $=470 \mathrm{Kg}$ \\
\hline \multicolumn{2}{|l|}{ Harga bahan lining : } \\
\hline$\checkmark$ magnesit $(\mathrm{MgO}) 90 \mathrm{Kg}$ & $\begin{array}{l}@ \operatorname{Rp} 8.900 / \mathrm{Kg} \\
=\operatorname{Rp} 881.000,00\end{array}$ \\
\hline$\checkmark$ Semen Coil $20 \mathrm{Kg}$ & $\begin{array}{l}@ \operatorname{Rp} 35.000 / \mathrm{Kg} \\
=\operatorname{Rp} 700.000,00\end{array}$ \\
\hline Harga lining former & $=\operatorname{Rp} 1.250 .000,00$ \\
\hline Harga asbes plate $2 \mathrm{lbr}$ & $\begin{array}{l}@ \operatorname{Rp} 75.000,00 \\
=\operatorname{Rp} 150.000,00\end{array}$ \\
\hline Ring Plate Mil Spider 2 pcs & $\begin{array}{l}@ \operatorname{Rp} 25.000,00 \\
=\operatorname{Rp} 50.000,00\end{array}$ \\
\hline Kawat las casting & $=\operatorname{Rp} 323.000,00$ \\
\hline Water glass (1kg) & $=\operatorname{Rp} 7.500,00$ \\
\hline \multicolumn{2}{|l|}{ Lama pengerjaan : } \\
\hline - $\quad$ Relining & $=3 \mathrm{Jam}$ \\
\hline - $\quad$ Sintering & $=5 \mathrm{jam}$ \\
\hline Upah kerja & $=\operatorname{Rp} 9000,00 /$ jam \\
\hline
\end{tabular}

Perhitungan biaya terdiri dari biaya penggunaan bahan, biaya pengerjaan relining dan biaya penggunaan listrik. Perincian pembiayaan proses lining dan sintering dapat dilihat pada Tabel 3 dibawah ini.

TABEL 3. Biaya Lining / Charging sebelum perbaikan

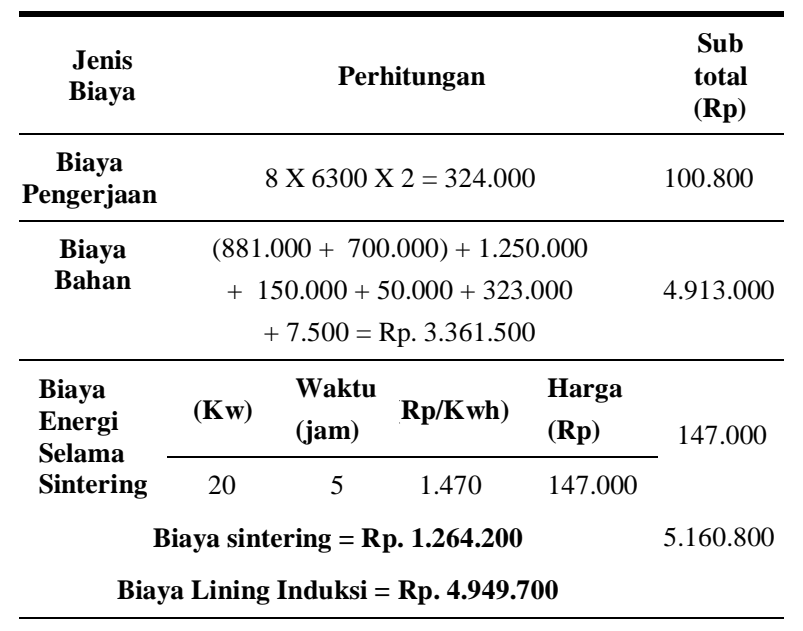

Sebelum perbaikan lining hanya bisa digunakan sebanyak $7 \mathrm{x}$ pemuatan atau $7 \mathrm{x}$ charging sehingga biaya perpemuatan sebesar:

$=$ Rp. $4.949 .700 / 7$

$=$ Rp. 707.100/ charging

Setelah dilakukan perbaikan Lining induksi dapat digunakan sebanyak 46 pemuatan atau 46 charging sehingga biaya Lining / Charging setelah perbaikan

$=$ Rp. 4.949.700/ 46

$=\mathrm{Rp} 107.602 /$ charging

\section{KESIMPULAN}

Penggunaan alat penumbuk diurutkan secara sistematis menurut bentuk dan fungsinya serta waktu yang sesuai dapat meningkatkan kepadatan lining. Kepadatan lining yang sesuai standar ini akan meningkatkan umur pemakaian lining tanur induksi.

Proses sintering hendaknya disesuaikan dengan diagram sintering bahan tahan api yang digunakan (alumino-silikat). Untuk mencapai uraian diagram sintering tersebut dilakukan langkah-langkah sebagai berikut: Peningkatan, penurunan dan penahanan power disesuaikan atau mengikuti temperatur kerja yang dibutuhkan.

Perbaikan proses penumbukan dan sintering akan meningkatkan penggunaan Tanur induksi dari 7x menjadi 46x. Peningkatan pemakaian ini menghasilkan penghematan biaya sebesar Rp.559.498 per Charging. Penghematan ini secara langsung akan berdampak pada harga material logam yang menjadi lebih murah.

\section{SARAN}

Pertama, Isu penelitian yang diungkap adalah Proses penumbukan dan sintering pada relining tanur induksi namun fokus penelitian pada proses penumbukan bahan lining. Pemilihan ini berdampak pada generalisasi studi yang bersifat terbatas.

Kedua, Penelitian ini hanya Memperhatikan proses kerja belum memperhatikan waktu pengerjaan atau variabel lain yang memungkinkan mempengaruhi umur lining. 


\section{DAFTAR PUSTAKA}

ASM Handbook 1992. Casting, Volume 15, ASM International.

Cardarelli, F., 2008. Materials Handbook Second Edition, Springer, London

Ghosh, A 2000. Secondary Steelmaking: Principles and Applications, CRC Press, 2000

Gandhewar, V.R., Bansod, S.V. and Borade, A.B., 2011. Induction furnace-A review. International Journal of Engineering and Technology, 3(4), pp.277-284.

Nugroho, S. and Umardhani, Y., 2011. Karakterisasi material Refraktori Basa Berbahan Dasar Magnesia (MgO) Guna Lining Tungku Induksi Pengecoran Baja di PT X Klaten. Prosiding SNST Fakultas Teknik, 1(1), UNWAHAS.

Surdia, T., dan Chijiiwa, K., 1986, Teknik Pengecoran Logam, Pradnya Paramita, Jakarta

www.hapli.wordpress.com, Peleburan Dengan Tanur Induksi, Lining Tanur Induksi. Diakses 11 Januari 2020

https://logamceper.com/teknik-pembuatancetakan-secara-manual, diakses 10 Januari 2020 